\title{
Social facilitation of eating behavior in young opossums: II. The effects of isolation'
}

JEROME J. PLATT, SLIPPERY ROCK STATE COLLEGE LOUIS W. SUTKER AND W. T. JAMES, UNIVERSITY OF GEORGIA

A litter of eight young opossums, in which social facilitation of eating behavior had previously been demonstrated, were separated at approximately 140 days of age ( 80 days from the pouch) into two groups of four. One group lived and was fed for the next 62 days in a common cage, while the second group lived and was fed for this period in individual cages which prevented visual or tactual contact with other animals. At the end of this period, social facilitation of eating behavior was found to be markedly present for the group raised in isolation $(p<.005)$, but was absent for the group raised in the common cage. The $S$ s raised in isolation also demonstrated significantly more emotionality $(p<.001)$ and aggressiveness $(p<.001)$ than did the $S$ s raised under the group condition.

The results of a previous investigation (Platt \& James, 1966) indicated the existence of social facilitation of eating behavior in a litter of young opossums. The Ss while in a group feeding situation continually ate more than when fed alone. While this phenomenon has been demonstrated in a wide variety of species (see James, 1960), relatively little research has been undertaken to determine the underlying basis of this behavior.

One problem appears to be the nature of social facilitation of eating behavior. Is it based on learning, or does it arise relatively independently of learning? This question was answered, in dogs at least, by James \& Gilbert (1955), who investigated the differences in social facilitation of eating in groups of dogs which had been fed together and separately for 90 days after weaning. It was found that for the animals fed in groups, social facilitation was present from the start of the experiment. For the animals fed in isolation, however, social facilitation was not present at first, and did not appear until about the 14th day of group feeding. James and Gilbert thus concluded that the lack of social facilitation in the experimental group was not due to a maturational factor since the effect was present in the control group. Furthermore, since the dogs were together in all activities except for feeding, this effect did not generalize from other social activities. The authors suggested that social facilitation was a result of learned secondary reinforcement. The present study was undertaken to see if similar findings would be obtained with opossums.

Method

Subjects. Eight young opossums (Didelphis marsupialis virginiana), five male and three female, were used as $\mathrm{Ss}$ in the current study. The Ss were all from the same litter and had been removed from the mother's pouch at approximately 60 days of age. The Ss had been weaned 16 days after removal from the pouch, and from age 85 days to 105 days they had been utilized in a study investigating the presence of social facilitation of eating behavior (Platt \& James, 1966). Since weaning, Ss had lived in a large common wire cage and were always fed together. Water was available ad $\mathrm{lib}$. The Ss were 140 days of age at the start of the present study ( 80 days from the pouch).

Procedure. At 140 days of age, Ss were divided into two groups of four. One group continued to live in the common cage, while the other was removed and each $\mathrm{S}$ placed in an individual cage, approximately 14 in. $x 14$ in. $x 20$ in. deep. These cages were enclosed on all sides by walls except for the fronts which were covered with wire screen. The cages were placed so that no animal could see another. The Ss were fed once daily on a ration of dog chow mixed with water, and care was taken to insure that all Ss received the same amount of food at each daily feeding. After 62 days, both groups of Ss, isolate and social, were examined independently for the presence of social facilitation of eating behavior. The test procedure followed was essentially the same as that reported in an earlier paper (Platt \& James, 1966), except that, in addition, two of the Es rated Ss daily on a 4 point scale of aggressiveness, and defecations in the feeding situation were recorded.

Results

Table 1 presents the mean daily food intake under the individual and social feeding conditions in terms of per cent of body weight. The data were analyzed by means of a 2 by 2 by 7 repeated measures analysis of variance design. Factor A was condition Ss were raised under (social vs isolate), Factor B was mode of feeding (group vs individual), and Factor $C$ was trials ( seven under each condition). The results of the analysis of variance indicated that mode of feeding (Factor A) approached, but did not quite reach significance at the .05 level (obtained $F=5.34$, $\mathrm{df}=1 / 6$, tabled $\mathbf{F}=5.99$ ). Condition of raising (Factor $B$ ) was not

Table 1. Daily Average Food Intake Per Animal (Expressed as Percentage of Body Weight.

\begin{tabular}{lccc} 
& Individual Feedings & Group Feedings & $\overrightarrow{\mathrm{X}}$ \\
\hline $\begin{array}{l}\text { Raised } \\
\text { Apart }\end{array}$ & 10.14 & 13.45 & 11.79 \\
$\begin{array}{l}\text { Raised } \\
\text { Together }\end{array}$ & 9.74 & 9.80 & 9.77 \\
\hline$\overline{\mathrm{X}}$ & 9.94 & 11.62 & 10.78 \\
\hline
\end{tabular}


significant $(F=2.48, d f=1 / 6)$, while the trials factor (Factor $\mathrm{C}$ ) and the mode of feeding by trials interaction were highly significant, with $F s$ of $35.80(\mathrm{df}=6 / 36$, $p<.001)$ and $11.23(d f=6 / 36, p<.01)$ respectively. Since the primary interest in this study was in determining the effects upon food intake of the conditions Ss were raised under, a priori tests for the simple effects of $B$ at levels of A were carried out, following the procedure described by Winer (1962, p. 324). The results of this procedure indicated that the simple effect of $B$ at $a_{1}$ was highly significant (critical $t=7.41$, twotailed $p<.005$ ), while the effect of $B$ at $a_{2}$ was not significant. Thus the Ss raised under the group condition did not show social facilitation of eating behavior, while the Ss raised in isolation showed this effect very strongly.

When Es' ratings of Ss' aggressiveness were correlated using the Pearson formula, a product-moment correlation of .583 was obtained, which was significant at the .02 level $(t=2.58, d f=13)$. On the basis of this, Es' ratings for each $S$ were combined and analyzed by means of the Mann-Whitney U-test. A U of 1 was obtained, which corresponds to a $t$-score of 3.203 $(p<.001)$. Thus, Ss under the social and isolate conditions differed significantly in the amount of aggressiveness they displayed towards the Es and each other, with the isolate group being more aggressive. Emotionality was determined by means of Ss' defecation scores. The number of Ss defecating in the feeding situation daily for each group was recorded, and a $x^{2}$ test was carried out to determine if the two groups differed significantly. The obtained $x^{2}$ of $16 \quad(\mathrm{df}=1)$ was significant beyond the .001 level, with the Ss raised in isolation accounting for almost all the defecations.

\section{Discussion}

The major finding of this study is that opossums raised in isolation show social facilitation of eating behavior, increased levels of emotionality, and aggressiveness, when compared with litter-mates raised under social conditions. These results are seemingly incompatable with an explanation of social facilitation of eating behavior in terms of secondary reinforcement, as suggested by one of the authors in an earlier paper (James \& Gilbert, 1955).

It may be that behavior in the feeding stiuation reflects the different amounts of social behavior en- gaged in by different species under normal life conditions. For instance, while not much is known about the life habits of the opossum in the wild, they appear to lead a solitary existence and do not thrive when placed under social conditions. Having isolated the young opossums may have speeded up whatever processes operate to produce solitary habits in adulthood. Thus, for the animals raised in isolation, social facilitation may have been the result of competition for available food in the feeding situation more so than for those raised under the social condition. The presence of an unconditioned consummatory response elicited by the presence of other animals would appear to have survival value for the individual opossum while in the litter. At a later age, however, when the individual is capable of foraging for and providing his own food, he would stand a better chance of survival if he was not in close proximity to other members of the same species.

The high levels of emotionality and aggression on the part of the Ss raised in isolation are more typical of wild opossums captured as adults than of opossums raised in the laboratory. That these behaviors were exhibited by Ss who also showed social facilitation appears to support an interpretation in terms of competition for available food supplies.

The design of the present study differed from that of James \& Gilbert (1955) in that their Ss were not raised in isolation, but rather, were just fed in isolation. Replication of their design with opossums or the current one with puppies may result in interesting findings.

\section{References}

JAMES, W. T. The development of social facilitation of eating in puppies. J. genet. Psychol., 1960, 96, 123-127.

JAMES, W. T., \& GILBERT, T. F. The effect of social facilitation on food intake of puppies fed separately and together for the first 90 days of life. Brit. J. Anim. Behav., 1955, 111, 131-133.

PLATT, J. J., \& JAMES, W. T. Social facilitation of eating behavior in young opossums: I. Group vs solitary feeding. Psychon. Sci., 1966, $6,421-422$.

WINER, B. J. Statistical principles in experimental design. New York: McGraw-Hill, 1962.

Note

1. A preliminary report of this study was presented to the Southern Society for Philosophy and Psychology at its annual meeting, Roanoke, Va., March, 1967. This research was supported in part by the Office of General Research of the University of Georgia, and was conducted during the senior author's tenure as a N. A. S. A. Predoctoral Trainee. 